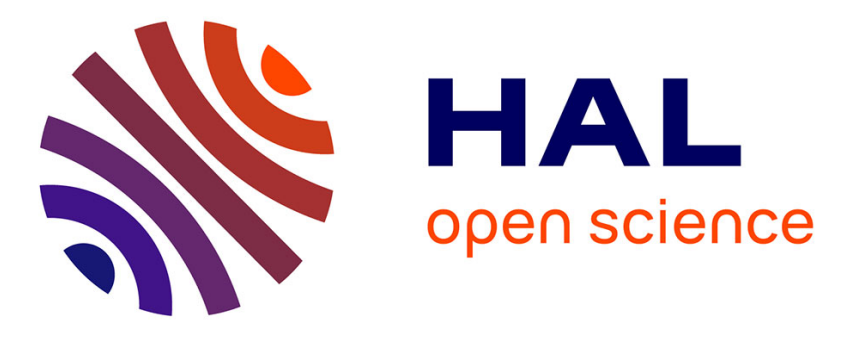

\title{
Primary central nervous system lymphoma in the elderly: a multicentre retrospective analysis
}

Mascha Schuurmans, Jacoline E. Bromberg, Jeanette K Doorduijn, Philip Poortmans, Martin J Taphoorn, Tatjana Seute, Roelien H Enting, Gustaaf Willem van Imhoff, Yvette van Norden, Martin J van den Bent

\section{To cite this version:}

Mascha Schuurmans, Jacoline E. Bromberg, Jeanette K Doorduijn, Philip Poortmans, Martin J Taphoorn, et al.. Primary central nervous system lymphoma in the elderly: a multicentre retrospective analysis. British Journal of Haematology, 2010, 151 (2), pp.179. 10.1111/j.1365-2141.2010.08328.x . hal-00569408

\section{HAL Id: hal-00569408 \\ https://hal.science/hal-00569408}

Submitted on 25 Feb 2011

HAL is a multi-disciplinary open access archive for the deposit and dissemination of scientific research documents, whether they are published or not. The documents may come from teaching and research institutions in France or abroad, or from public or private research centers.
L'archive ouverte pluridisciplinaire HAL, est destinée au dépôt et à la diffusion de documents scientifiques de niveau recherche, publiés ou non, émanant des établissements d'enseignement et de recherche français ou étrangers, des laboratoires publics ou privés. 


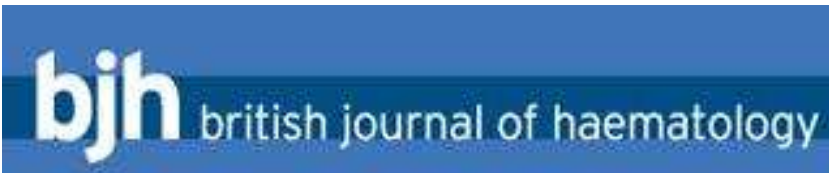

\section{Primary central nervous system lymphoma in the elderly: a multicentre retrospective analysis}

\begin{tabular}{|c|c|}
\hline Journal: & British Journal of Haematology \\
\hline Manuscript ID: & BJH-2010-00481.R1 \\
\hline Manuscript Type: & Ordinary Papers \\
\hline $\begin{array}{r}\text { Date Submitted by the } \\
\text { Author: }\end{array}$ & 10-Jun-2010 \\
\hline Complete List of Authors: & $\begin{array}{l}\text { Schuurmans, Mascha; Leeuwarden medical Centre, neurology } \\
\text { Bromberg, Jacoline; Erasmus MC University medical Centre / Daniel } \\
\text { den Hoed Cancer centre, Neuro-Oncology } \\
\text { Doorduijn, Jeanette; Erasmus MC University Medical Centre / Daniel } \\
\text { den Hoed Cancer Centre, haematology } \\
\text { Poortmans, Philip; Bernard Verbeeten Institute for Radiotherapy, } \\
\text { Radiotherapy } \\
\text { Taphoorn, Martin; Medical Centre Haaglanden, Neurology } \\
\text { Seute, Tatjana; Utrecht university Medical Centre, Neurology } \\
\text { Enting, Roelien; Groningen University Medical Centre, Neurology } \\
\text { van Imhoff, Gustaaf; University Medical Center Groningen, } \\
\text { Haematology } \\
\text { van Norden, Yvette; Erasmus MC University Medical Centre / Daniel } \\
\text { den Hoed Cancer Centre, Trials and Statistics } \\
\text { van den Bent, Martin; Erasmus MC University Medical Centre / } \\
\text { Daniel den Hoed Cancer Centre, neuro-oncology }\end{array}$ \\
\hline Key Words: & $\begin{array}{l}\text { CNS, ELDERLY, NON-HODGKIN-S LYMPHOMA, RADIOTHERAPY, } \\
\text { CHEMOTHERAPY }\end{array}$ \\
\hline
\end{tabular}

\section{S ScholaroNE


Bromberg, PCNSL in the elderly

\title{
Primary central nervous system lymphoma in the elderly:
}

\section{a multicentre retrospective analysis}

\author{
M. Schuurmans, ${ }^{(1)}$ J.E.C. Bromberg, ${ }^{(1)}$ J. Doorduijn, ${ }^{(2)}$ Ph. Poortmans,${ }^{(3)}$ M.J.B.Taphoorn, ${ }^{(4)}$ \\ T. Seute, ${ }^{(5)}$ R.Enting ${ }^{(6)}$ G.van Imhoff ${ }^{(7)}$ Y.van Norden, ${ }^{(8)}$ M.J.van den Bent. ${ }^{(1)}$
}

ErasmusMC, Daniël den Hoed Cancer Center, Rotterdam, departments of Neuro-Oncology ${ }^{(1)}$,

hematology ${ }^{(2)}$, and trials and statistics; ${ }^{(8)}$ Bernard Verbeeten Institute for radiotherapy ${ }^{(3)}$; MC

Haaglanden, department of Neurology ${ }^{(4)}$; Utrecht University Medical Center department of

Neurology ${ }^{(5)}$; Groningen University Medical Center , departments of neurology ${ }^{(6)}$ and Hematology ${ }^{(7)}$

Running title: PCNSL in the elderly 
Bromberg, PCNSL in the elderly

Corresponding author:

Jacoline E.C. Bromberg MD

Dept Neuro-Oncology

Daniel den Hoed Cancer Center / Erasmus University Medical Center

PO Box 5201

3008 AE Rotterdam

The Netherlands

Tel +31 107041415

Fax: +31 107041031

email: j.bromberg@erasmusmc.nl

There are no conflicts of interest, no funding source 
Bromberg, PCNSL in the elderly

\section{Summary}

Elderly patients with primary CNS lymphoma (PCNSL) do not tolerate treatment with combined radio-chemotherapy well because of leuko-encephalopathy and are usually treated initially with chemotherapy or radiotherapy alone. Little is known about efficacy and toxicity of these treatments outside clinical studies.

Methods: retrospective analysis of all patients aged 60 or over admitted with PCNSL to one of 5 Dutch centers between 1998 and 2007.

Results: 74 patients were identified. 29 were treated with radiotherapy only (group A), in 36 intended treatment was chemotherapy alone (group B), in 9 intended treatment was chemotherapy followed by radiotherapy (group C). Median OS was 20 months;.4 months in patients with KPS $<70,25$ months in patients with $\mathrm{KPS} \geq 70$ (p<0.001). Treatment modality was not an independent prognostic factor. Forty patients were treated with MTX $3 \mathrm{~g} / \mathrm{m}^{2}$ : there were 2 toxic deaths. Ten patients discontinued chemotherapy because of toxicity. Delayed encephalopathy was reported in 10 patients. Conclusion: Community hospitals still utilize WBRT frequently in elderly PCNSL patients, though a majority tolerates chemotherapy well. Performance status was the most important variable determining prognosis. Short and long term toxicities must be weighed against possible clinical benefits of each treatment, making treatment decisions a highly individualized process. 
Bromberg, PCNSL in the elderly

Key words: CNS lymphoma, radiotherapy, chemotherapy, age, performance status 


\section{Introduction}

Primary central system lymphoma (PCNSL) is a non-Hodgkin lymphoma that arises within the brain, spinal cord, cerebrospinal fluid or eyes in the absence of systemic disease. Given the median age at diagnosis of 55-65 yrs, a large proportion of patients is over 60 and age has a profound influence on prognosis and treatment choices.(Abrey et al 2006, Panageas et al 2007)

Radiotherapy alone has shown a disappointing median survival time of only 5-7 months in older patients, although one retrospective study describes a median survival of 12 months (Nelson et al, 1992, Laack et al 2006, Panageas et al, 2007, Shibamoto et al 2005). Chemotherapeutic regimens with high-dose methotrexate (HD-MTX) based chemotherapy followed by whole brain radiotherapy (WBRT), have resulted in long term remissions and improved survival rates (De Angelis et al, 2002, Batchelor et al, 2006). However, combined treatment results in delayed neurotoxicity in $24-83 \%$ of patients and is more common in patients aged $>\mathbf{6 0}$ years (Blay et al, 1998, Omuro et al, 2005, Wassenberg et al, 2001). The efficacy of chemotherapy used alone as initial treatment was reported to be at least comparable to that of RT alone in terms of survival benefit and compares favourably to combined treatment as well as radiotherapy alone in terms of delayed neurotoxicity (Ekenel et al, 2008, Hoang-Xuan et al, 2003). However, inclusion biases in clinical studies have a great impact on the outcome, and these trials do not necessarily reflect the outcome of treatment in a more general, aselect population. One recently published populationbased study showed that a majority of patients is still treated with radiotherapy alone and supports the notion that outcome in an aselect population may not be the same as 
Bromberg, PCNSL in the elderly

\section{that in prospective clinical studies (Panageas et al 2007, Abrey et al 2006, Pels et al} 2003).

Little is known about the use or the relative efficacy and toxicity of chemotherapy, radiotherapy and combined treatment in the elderly population outside of clinical trials. Furthermore, the strategy of leaving out consolidation radiotherapy after brief, intensive chemotherapy in responsive patients has not been evaluated. We therefore studied the outcome of an unselected patient population with PCNSL over the age of 60.

\section{Methods}

In 5 large Dutch hospitals, 3 academic and 2 non-academic teaching hospitals, all patients aged 60 or above who were HIV negative and diagnosed with histologically proven nonEBV associated PCNSL from 1998-2007 were identified from the neuropathology, neurooncology and radiotherapy databases. Patient files for all these patients were reviewed; data on age, extent of disease, performance status, treatment modality, toxicity and survival were collected. As primary endpoint for efficacy overall survival was used. Late neurotoxicity or encephalopathy was diagnosed when both cognitive decline was reported and diffuse white matter lesions were shown on MRI. Survival data were calculated from the date of diagnosis to the date of documented progression or additional treatment (event-free survival, EFS) or death (overall survival, OS). A multivariate cox regression analysis was used to evaluate the prognostic value of age, performance status and type of treatment. 
Bromberg, PCNSL in the elderly

\section{Results}

\section{Patient characteristics;}

One hundred and eleven patients were identified who were diagnosed with PCNSL. All patients were HIV-negative. Thirty-seven patients were excluded from further analysis for the following reasons. Twenty-four patients were not treated because their condition had been considered to be too poor. Three patients had EBV positive lymphoma. In 5 patients the lymphoma was confined to the eyes. Since isolated ocular lymphoma may have a different prognosis from PCNSL in general we excluded these patients from the analysis. Five patients had been lost to follow up.

Seventy-four patients with confirmed PCNSL who received treatment remained for further analysis. In this group the median age was 65 (range 60-82) and the KPS $70 \%$ (range 30100). There were 34 women and 40 men. Pathology was DLBCL in all patients.

\section{Treatment and outcome:}

Patients were categorized into three groups according to the intended treatment: group A, radiotherapy only $(n=29)$, group $B$, chemotherapy only $(n=36)$ and group $C$, combined treatment $(n=9)$. Of the 36 patients who had received chemotherapy only as the primary treatment, five had been treated with low-dose MTX $(500 \mathrm{mg} / \mathrm{m} 2)$. As this dose is to be considered inadequate because of insufficient CNS penetration, these patients were excluded from all further analyses so that 31 patients remained in group B. A flowchart of all patients is shown in figure 1. Clinical characteristics for the 3 treatment groups are shown in table 1. Response and survival data for the treatment groups are summarized in table 2. Overall survival (OS) as determined by age and performance status is shown in figure 3 . The median 
Bromberg, PCNSL in the elderly

OS for treated patients was 21 months. Survival for the 24 patients who were not treated was 1 month, their median age was 71 and their median KPS 50. (data not shown).

The 29 patients in group A, treated with whole brain radiotherapy only, received a median dose of 32 Gy (range 18-50 Gy). Median OS in this group was 7 months. For a large proportion of patients in group A no date of progression was available so that EFS could not be reliably calculated. The the 1 -year OS was $41 \%$.

\begin{abstract}
All nine patients in group $\mathrm{C}$, intended to be treated by chemotherapy followed by radiotherapy had been treated with the combined MBVP scheme (MTX $3 \mathrm{~g} / \mathrm{m}^{2}$, dexamethasone, BCNU and teniposide) followed by 40 Gy WBRT. (Poortmans et al, 2003) Seven of them were also treated intrathecally according to protocol. In this group PFS and OS at 1 year were $100 \%$.
\end{abstract}

Of the 31 patients in group B, who had been intended to be treated with chemotherapy only, 24 had also been treated with the combined MBVP scheme. The 7 other patients had received HD-MTX monotherapy: six of them received $3 \mathrm{~g} / \mathrm{m}^{2}$, one received $1.5 \mathrm{~g} / \mathrm{m}^{2}$. All except seven patients in group B were also treated intrathecally. Sixteen of the 31 patients in group B were additionally treated with radiotherapy after completion or abortion of chemotherapy because of toxicity $(n=7)$, insufficient response $(n=5)$, or recurrence $(n=3)$. In the other 15 patients MTX-based chemotherapy was the only treatment given. In some cases this was because no progression was observed, in others because no further treatment was regarded feasible by the treating physician. In group B as a whole the EFS was 3 months and the OS 23 months. The 1-year survival rate was $56 \%$. OS of the 15 patients treated with chemotherapy who were never irradiated ranged from 1-66 months with a median of 13 months. 
Bromberg, PCNSL in the elderly

On multivariate analysis there was no difference in overall survival between the treatment groups A, B and C: relative Hazard Ratio (HR) 0.9, 95\% confidence interval (CI) 0.58-1.4. Performance status and age did correlate with survival: for performance status the relative HR was $0.33,95 \%$ CI $0.17-0.64, p=0.001$, (figure 2). For age the relative HR was $2.33,95 \% \mathrm{CI}$ $1.18-4.59, \mathrm{p}=0.01$

\section{Toxicity:}

Of the 40 patients receiving HD-MTX, 12 suffered complications. Two fatal toxicities occurred in the chemotherapy treated patients: one patient died from neutropenic sepsis, the other developed fatal toxic epidermolysis. In 10 other patients $(25 \%)$ chemotherapy was discontinued because of toxicity (nefrotoxicity, pulmonary toxicity or haematological toxicity), in all these cases only one cycle was given. Two of these patients received no further treatment, the other 8 received radiotherapy; this was pre-planned in one of them.

Late neurotoxicity was documented in 10 patients (13.5\%) after a median of 17.5 months (range 6 -50). Four of these patients were in group A three in group B (two salvaged with radiotherapy) and three in group C. Median follow-up in all surviving patients was 20.4 months; in group A 13.5, group B 19.8 and group C 37.3 months. The incidence of encephalopathy increased with survival time: two years after diagnosis $30 \%$ of surviving patients had documented encephalopathy and after 3 years encephalopathy was found in $70 \%$.

\section{Cause of death}

Fifty-two patients (75\%) died, 24/29 in group A, 24/31 in group B and 4/9 in group C. Cause of death was disease progression in 35 (67\%; ( 18 in group A, 15 in B of which two 
had systemic recurrence, and two in $\mathrm{C})$, infections in seven (13\%; (two in A, three in B and two in C), and other causes in 10 (19\%; (four in A, six in B).

\section{Discussion}

Older patients, aged > 60, account for approximately half the cases of PCNSL. Age has long been recognized as an important prognostic factor in PCNSL and profoundly influences treatment choices in routine clinical practice. Recent phase II studies have emphasized the role of chemotherapy, but as a rule phase II studies are biased by patient selection. In our study of unselected older patients in academic and teaching hospitals we found that $42 \%$ of patients was treated with radiotherapy only, $45 \%$ was initially treated with chemotherapy alone and $9 / 69(13 \%)$ with combined treatment from the outset. This is similar to results of a published population-based survey, and shows that monotherapy with WBRT is still common practice outside clinical trials. (Panageas et al 2007) However, in the data of Panageas et al no correlation could be made with clinical factors as it was based on the SEER and Medicare registrations only. In our study median age was higher in patients treated with radiotherapy only (group A) than in the other two groups (70 vs 63 yrs) and performance status was better in the group treated with combination therapy (group C), with a median KPS 80 compared with median KPS 70 in the other groups, showing that indeed age and performance status played a role in treatment decisions.

We found that outcome was influenced most by performance status. Median survival was 25 months in patients with a KPS $\geq 70$ and 4 months in patients with a KPS $<70$ 
(relative HR 0.33, 95\% CI 0.17-0.64, $\mathrm{p}=\mathbf{0 . 0 0 1}$ ). Age had less influence (relative HR 2.33, $95 \%$ CI $1.18-4.59, p=0.01$ ) in this population of patients aged over 60. Although treatment modality was not an independent risk factor, as stated, prognostic factors were not balanced between the groups. Age and performance status are the two variables that have been consistently identified as independent prognostic factors in several studies (Abrey et al, 2006, Ferreri et al, 2003, Pels et al 2003). In daily practice these factors are used to determine treatment choices. Their prognostic value seems to hold true across the various treatments although the worse prognosis we found in patients with poor performance status may in part have been determined by treatment choices. Whether patients, in whom poor performance status was determined by the neurological effects of the disease rather than by comorbidity, would do better had they been treated more intensively is still an unanswered question.

Response to treatment (table 2) was similar in both single modality treatment groups, but EFS was disappointlingly short in group B, intended to be treated with chemotherapy only. In 7/31 patients in group B WBRT was given after abortion of chemotherapy due to toxicity. Although this does not necessarily mean the chemotherapy was ineffective it does denote failure of the chemotherapy-only strategy and was therefore included as failure in the EFS analysis. Contrary to some centres in other countries, in the Netherlands salvage chemotherapy for primary CNS lymphoma is rarely given so that 16/31 patients in group B were ultimately irradiated. Nevertheless, even among patients who never received radiotherapy median OS was 23 months with survival ranging up to 66 months. Despite the short EFS, the median OS of 23 months is comparable to published results of prospective studies of chemotherapy-only regimens in older patients in whom median survival has ranged between 14 and 34 months.(Hoang-Xuan et al 
Bromberg, PCNSL in the elderly

2003, Illerhaus et al 2009, Omuro et al 2007, Pels et al 2003) However, in these studies salvage WBRT was either utilized less frequently than in our patients or not reported.

\begin{abstract}
Although the short EFS in our group B is indicative of limited long-term efficacy of MBVP chemotherapy alone in the group as a whole, a minority of patients is able to attain long survival with MBVP chemotherapy only. This suggests that a subset of elderly patients has an extremely chemotherapy-sensitive PCNSL; a phenomenon that was also found by others (Pels et al, 2003, Omuro et al, 2007) Nonetheless, for only a small number of patients in our population chemotherapy alone sufficed: most patients relapsed or progressed and clearly more effective chemotherapy or effective maintenance chemotherapy is needed.
\end{abstract}

In group A (radiotherapy only) median OS was 7 months. This is comparable to results in most (Nelson et al, 1992, Laack et al 2006, Panageas et al, 2007) but not all published studies. (Shibamoto et al 2005) The first three are prospective phase II or populationbased studies, the last was a multicentre retrospective study without details on treated patients not included in the study. Thus inclusion and recall biases may have played a role in the differing survival data.

Patients in group C (predetermined combined treatment) did especially well in our study. It must be born in mind, however, that both age and performance status were more favourable in group $C$ than in the other groups, suggestive of patient selection. Although the small number of patients in this group and the retrospective nature of the study preclude definitive conclusions, OS in group B, in which many patients were treated with radiotherapy after failure of chemotherapy, also appeared superior to that in group A. This suggests that combined treatment, even when there is a time interval between chemotherapy and radiotherapy, may be more efficacious than either single modality alone. In prior studies 
Bromberg, PCNSL in the elderly

salvage radiotherapy after failure of primary treatment with chemotherapy alone was also found to be effective.(Nguyen et al, 2005, Hottinger et al, 2007)

The acute chemotherapy toxicity was generally acceptable. Most patients (75\%) received HDMTX treatment without major problems. In 10 patients the toxicity was reason for discontinuation of chemotherapy. Myelosuppression was the most frequent side effect of the treatment and occurred mainly during the first cycle. Other acute side effects of MTX-based chemotherapy that were reported in our patient group consisted of renal dysfunction and pulmonary toxicity. The toxicity data are, however, slightly higher than those reported in the younger population in which severe toxicity is reported in about 5-10\% (Jahnke et al, 2005). Despite the common perception that high-dose MTX is too toxic for the elderly, our data confirm the observations of others (Jahnke et al, 2005, Illerhaus et al, 2009, $\mathrm{Ng}$ et al, 2000) that the majority of older patients can tolerate high-dose MTX, provided their renal function is adequate.

In our population neurocognitive testing was not routinely performed. Nevertheless clinically relevant encephalopathy was reported in 10 patients. Nine of them had been treated with radiotherapy, 5 with both chemotherapy and radiotherapy; among them 3 of the 8 patients from group C who survived more than 1 year. The incidence of encephalopathy increased with survival time: two years after diagnosis $30 \%$ of surviving patients were found to suffer from neurotoxicity, after 3 years this had increased to $70 \%$ of surviving patients. This is compatible with previously published data (Omuro et al, 2005, Blay et al, 1998, Wassenberg et $a l, 2001)$ and underscores the necessity of avoiding radiotherapy in elderly patients if possible. 
Bromberg, PCNSL in the elderly

In conclusion, treatment of elderly patients outside clinical trials is varied and WBRT alone is still utilized frequently. Although our chemotherapy-only results obtained in a community hospital setting appear somewhat inferior to those obtained in published prospective studies they do support tolerability of HD-MTX-based regimens in selected elderly patients. Performance status seems to be the most important prognostic factor for outcome and should be used in combination with comorbidities to tailor treatment to the individual patient. Radiotherapy should be reserved for refractory disease, considering the high rate of neurotoxicity, and for patients not fit for chemotherapy. However, only a minority of patients in our population was able to attain long term survival with MTX-based chemotherapy without additional radiotherapy. More effective chemotherapy regimens are needed to further postpone radiotherapy and to increase overall survival. Randomized multicentre studies are needed to define optimal treatment for this patient population. 
Bromberg, PCNSL in the elderly

\section{References}

Abrey, L., Yahalom, J. \& DeAngelis, L. (2000) Treatment for primary CNS lymphoma: the next step. Journal of Clinical Oncology, 18, 3144-3150.

Abrey, L., Ben-Porat, L., Panageas, K.S,, Yahalom, J., Berkey, B., Curran, W., Schultz, C., Leibel, S., Nelson, D., Mehta, M. \& DeAngelis, L.M. (2006) Primary central nervous system lymphoma:The Memoraial Sloan-Kettering Cancer Center prognostic model. Journal of Clinical Oncology, 24, 5711-5715.

Batchelor, T. \& Loeffler, J.S. (2006) Primary CNS lymphoma. Journal of Clinical Oncology, 24 (8), 1281-1288.

Bessell, E.M., Hoang-Xuan, K., Ferreri, A.J. \& Reni, M. (2007) Primary central nervous system lymphoma: biological aspects and controversies in management. European Journal of Cancer, 43 (7), 1141-1152.

Blay, J.Y., Conroy, T., Chevreau, C., Thyss, A., Quesnel, N., Eghbali, H., Bouabdallah, R., Coiffier, B., Wagner, J.P., Le Mevel, A., Dramais-Marcel, D., Baumelou, E., Chauvin, F. \& Biron, P. (1998) High-dose methotrexate for the treatment of primary cerebral lymphomas: analysis of survival and late neurologic toxicity in a retrospective series. Journal of Clinical Oncology, 16 (3), 864-871.

DeAngelis, L., Seiferheld, W., Schold, S., Fisher, B. \& Schultz, C. (2002) Combination chemotherapy and radiotherapy for primary central nervous system lymphoma: Radiation Therapy Oncology Group Study 93-10. Journal of Clinical Oncology, 20, 4643-4648.

Ekenel, M., Iwamoto, F.M., Ben Porat, L.S., Panageas, K.S., Yahalom, J., DeAngelis, L.M. \& Abrey, L.E. (2008) Primary central nervous system lymphoma: the role of 
Bromberg, PCNSL in the elderly

consolidation treatment after a complete response to high-dose methotrexate-based chemotherapy. Cancer, 113 (5), 1025-1031.

Ferreri, A.J.M., Blay, J.Y., Reni, M., Pasini, F., Spina, M., Ambrosetti, A., Calderoni, A., Rossi, A., Vavassori, V., Conconi, A., Devizzi, L., Berger, F., Ponzoni, M., Borisch, B., Tinguely, M., Cerati, M., Milani, M., Orvieto, E., Sanchez, J., Chevreau, C., Dell'Oro, S., Zucca, E. \& Cavalli, F. (2003) Prognostic scoring system for primary CNS lymphomas:The international extranodal lymphoma study group experience. Journal of Clinical Oncology, 21, 266-272.

Hoang-Xuan, K., Taillandier, L., Chinot, O., Soubeyran, P., Bogdhan, U., Hildebrand, J., Frenay, M., De Beule, N., Delattre, J.Y. \& Baron, B. (2003) Chemotherapy alone as initial treatment for primary CNS lymphoma in patients older than 60 years: a multicenterphase II study (26952) of the European Organization for Research and Treatment of Cancer Brain Tumor Group. Journal of Clinical Oncology, 21, 27262731.

Illerhaus, G., Marks, R., Muller, F., Ihorst, G., Feuerhake, F., Deckert, M., Ostertag, C. \& Finke, J. (2009) High-dose methotrexate combined with procarbazine and CCNU for primary CNS lymphoma in the elderly: results of a prospective pilot and phase II study. Annals of Oncology, 20 (2), 319-325.

Jahnke, K., Korfel, A., Martus, P., Weller, M., Herrlinger, U., Schmittel, A., Fischer, L. \& Thiel, E. On behalf of the German Primary Central Nervous System Lymphoma study Group (G-PCNL-SG) (2005) High-dose methotrexate toxicity in eldely patients with primary central nervous system lymphoma. Annals of Oncology, 16, 445-449.

Laack NN, Ballman KV, Brown PB, O'Neill BP. (2006) Whole-brain radiotherapy and high-dose methylprednisolone for elderly patients with primary central nervous system lymphoma: Results of North Central Cancer Treatment Group (NCCTG) 
Bromberg, PCNSL in the elderly

\title{
96-73-51. International Journal of Radiaton Oncology Biology and Physics, 65(5),1429-1439.
}

\author{
Nelson, D.F., Martz, K., Bonner, H., Nelson, J.S., Newall, J., Kerman, H.D., Thomson, J.W. \\ \& Murray, K.J. (1992) Non-Hodgkin's lymphoma of the brain: Can high dose, \\ large volume radiation therapy improve survival? Report on a prospective trial by \\ the Radiation Therapy Oncology Group (RTOG)-RTOG 8315. International \\ Journal of Radiaton Oncology Biology and Physics, 23, 9-17.
}

Ng, S., Rosenthal, M.A., Ashley, D. \& Cher, L. (2000) High-dose methotrexate for primary CNS lymphoma in the elderly. Neuro-Oncology, 2, 40-44.

Omuro, A.M.P., Ben-Porat, L.S., Panageas, K.S., Kim, A.K., Correa, D.D., Yahalom, J., DeAngelis, L.M. \& Abrey, L.E. (2005) Delayed neurotoxicity in primary central nervous system lymphoma. Archives of Neurology, 62, 1595-1600.

Omuro, A.M.P., Taillandier, L., Chinot, O., Carnin, C., Barrie, M. \& Hoang-Xuan, K. (2007) Temozolamide and methotrexate for primary central nervous system lymphoma in the elderly. Journal of Neuro-Oncology, 85, 207-211.

Panageas, K.S., Elkin, E.B., Ben-Porat, L., DeAngelis, L.M. \& Abrey, L.E. (2007) Patterns of treatment in older adults with primary central nervous system lymphoma. Cancer, 110, $1338-1344$.

Pels, H., Schmidt-Wolf, I.G., Glasmacher, A., Schulz, H., Engert, A., Diehl, V., Zellner, A., Schackert, G., Reichmann, H., Kroschinsky, F., Vogt-Schaden, M., Egerer, G., Bode, U., Schaller, C., Deckert, M., Fimmers, R., Helmstaedter, C., Atasay, A., Klockgether, T. \& Schlegel, U. (2003) Primary central nervous system lymphoma: results of a pilot and phase II study of systemic and intraventricular chemotherapy with deferred radiotherapy. Journal of Clinical Oncology, 21 (24), 4489-4495. 
Bromberg, PCNSL in the elderly

Pels H, Juergens A, Glasmacher,A., Schulz,H., Engert,A., Linnebank,M., Schackert,G., Reichmann,H., Kroschinsky,F., Vogt-Schaden,M. et al (2009) Early relapses in primary CNS lymphoma after response to polychemotherapy without intraventricular treatment: results of a phase II study. Journal of Neuro-Oncology, 91,299-305.

Poortmans, P.M., Kluin-Nelemans, H.C., Haaxma-Reiche, H., Van't Veer, M., Hansen, M., Soubeyran, P., Taphoorn, M., Thomas, J., Van den Bent, M., Fickers, M., Van Imhoff, G., Rozewicz, C., Teodorovic, I., Van Glabbeke, M. (2003) High-dose methotrexatebased chemotherapy followed by consolidating radiotherapy in non-AIDS-related primary central nervous system lymphoma: European Organization for Research and Treatment of Cancer Lymphoma Group Phase II Trial 20962. Journal of Clinical Oncology, 21 (24), 4483-4488.

Shibamoto Y, Ogino H, Hasegawa M, Suzuki K, Nishio M, Fujii T et al. (2005) Results of radiation monotherapy for primary central nervous system lymphoma in the 1990s. International Journal of Radiaton Oncology Biology and Physics, 62(3),809813.

Wassenberg, M.W., Bromberg, J.E., Witkamp, .D., Terhaard, C.H. \& Taphoorn, M.J. (2001) White matter lesions and encephalopathy in patients treated for primary central nervous system lymphoma. Journal of Neuro-Oncology, 52(1), 73-80. 
Figure 1. Description of patients with PCNSL identified

\section{Legends}

10

Figure 2. Overall Survival by Performance Status

Legend: $\mathrm{A}=\mathrm{KPS}<70 \% ; \mathrm{B}=\mathrm{KPS} \geq 70 \%$ 
Table 1. clinical and treatment characteristics

\begin{tabular}{|c|cccc|}
\hline & A & B & C & Total \\
\hline Total & 29 & 31 & 9 & 69 \\
Age median & 70 & 63 & 62 & 65 \\
KPS median & 70 & 70 & 80 & 70 \\
N age $<70$ & 14 & 27 & 9 & \\
N age $\geq 70$ & 15 & 4 & 0 & 50 \\
N KPS $<70$ & 13 & 11 & 0 & 19 \\
N KPS $\geq 70$ & 16 & 20 & 9 & 45 \\
\hline
\end{tabular}

group $A=$ radiotherapy only, group $B=$ by intention chemotherapy only, group $C=$ by intention chemotherapy + radiotherapy 
Table 2. survival and response

\begin{tabular}{|l|cccc|}
\hline & $\begin{array}{c}\text { Response } \\
(\text { CR + PR) }\end{array}$ & $\begin{array}{c}\text { Median PFS* } \\
\text { (range) }\end{array}$ & $\begin{array}{c}\text { Median OS* } \\
\text { (range) }\end{array}$ & 12 months \\
\hline Group A (n=29) & $69 \%$ & NA & $7(1-64)$ & $41 \%$ \\
Group B (n=31) & $71 \%$ & $3(2-66)$ & $23(2-66)$ & $56 \%$ \\
Group C (n=9) & $100 \%$ & NR (18-80) & NR (22-80) & $100 \%$ \\
Total $(n=69)$ & $74 \%$ & $7(\mathbf{1 - 8 0})$ & $21(\mathbf{1 - 8 0})$ & $56 \%$ \\
\hline
\end{tabular}

group $A=$ radiotherapy only, group $B=$ by intention chemotherapy only, group $C=$ by intention chemotherapy + radiotherapy

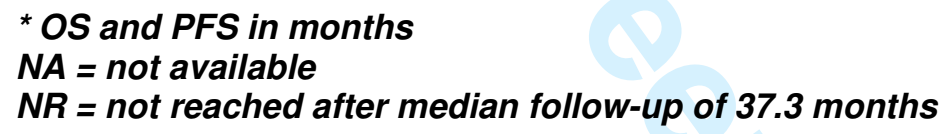




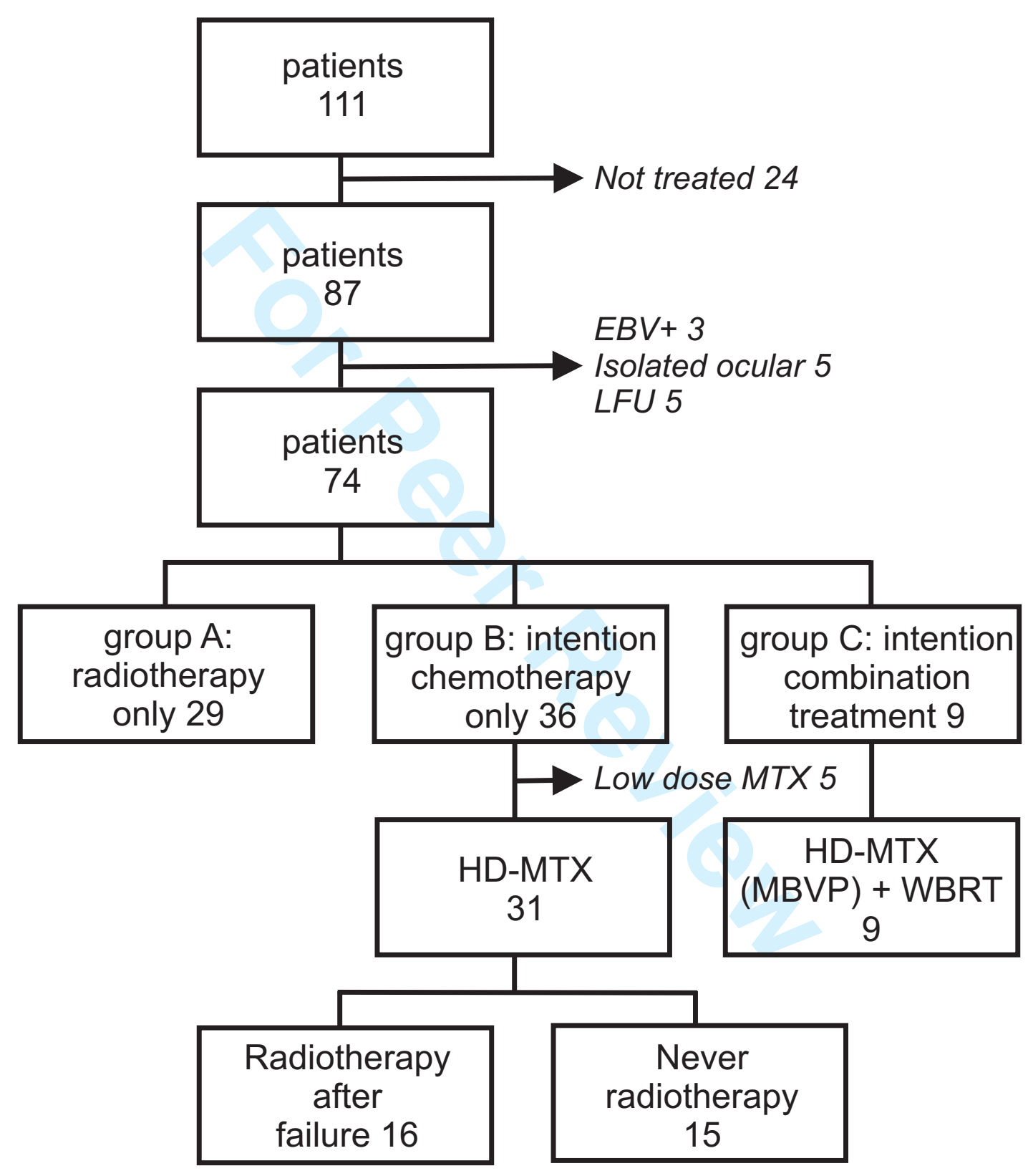




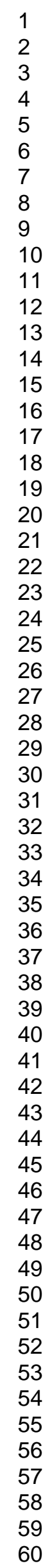

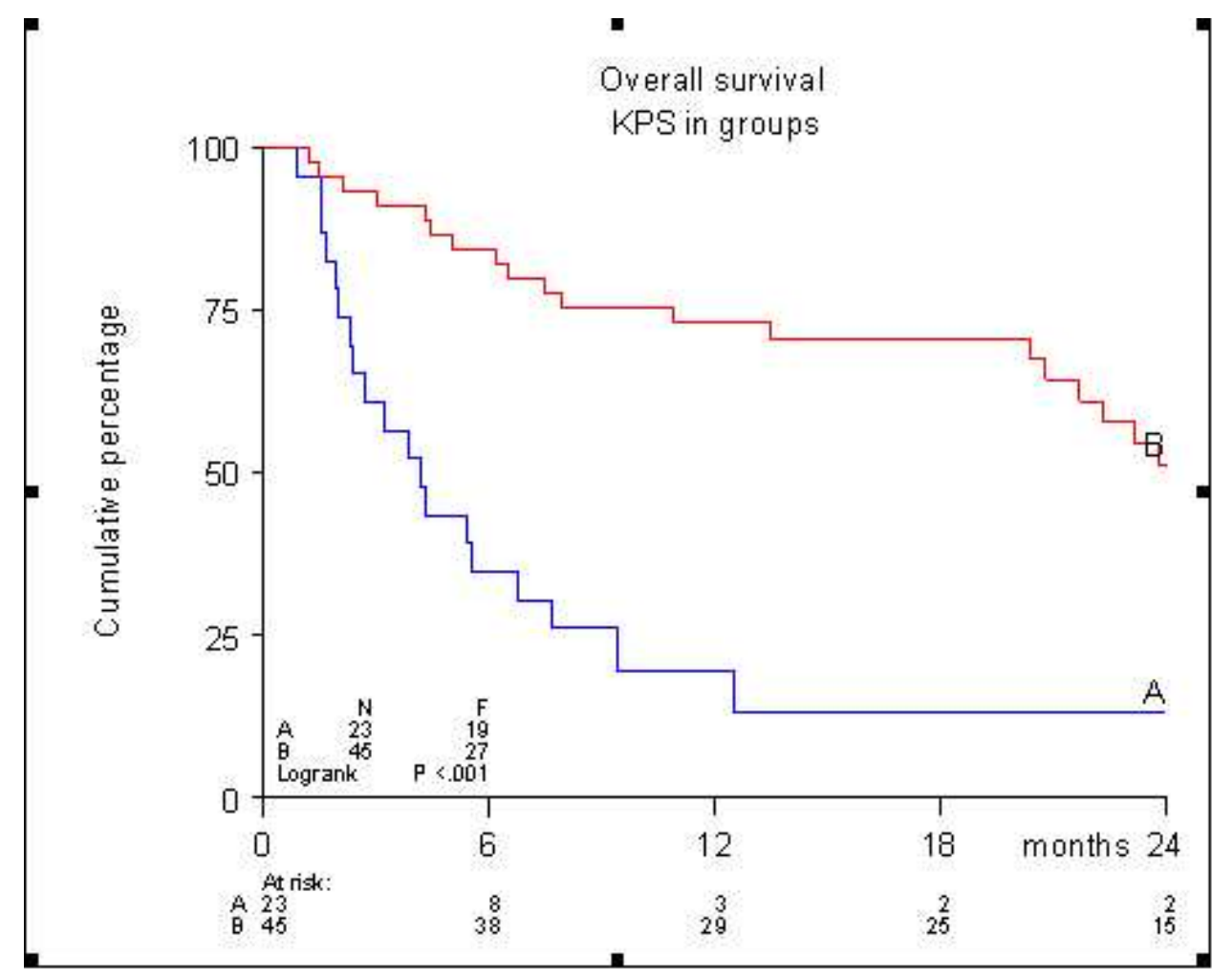

$43 \times 33 \mathrm{~mm}(300 \times 300$ DPI $)$ 